\title{
Virtual Education During the Pandemic: The Experience of a Medical Student
}

\author{
Hossein Yarmohammadi (iD) ${ }^{1, *}$ \\ ${ }^{1}$ Medical Students Research Committee, Mostafa Khomeini Hospital, Shahed University College of Medicine, Tehran, Iran \\ "Corresponding author: Medical Students Research Committee, Mostafa Khomeini Hospital, Shahed University College of Medicine, Italy Street, Keshavarz Blvd, Tehran, Iran. \\ Email: hosseinyarmohammadi98@gmail.com
}

Received 2020 August 24; Revised 2020 October 08; Accepted 2020 October 27.

Keywords: COVID-19, Medical Education, Virtual Education

\section{Dear Editor,}

Coronavirus Disease (COVID-19) has changed many aspects of our lives, including education. In Iran, the medical education system has been greatly affected, and universities and teaching hospitals are trying to minimize the possible negative effects (1). As a medical student that currently is working in the internal medicine department, I would like to share my experience regarding virtual education to indicate its pros and cons for medical students.

It was my first day as a stager in the internal medicine department, on 2020/2/22, and I was thrilled. But, suddenly, the rotation was cancelled due to the COVID-19 pandemic. The situation continued until 2020/6/10, that I came back and opened my locker room to wear my white coat and to start my second first day! Although several limitations were imposed due to the pandemic, our education continued (i.e. taking history and performing physical examination) with no break to the date of 2020/8/19. However, the duration of rotations was significantly shortened (compared to previous years that was four months), and I was concerned if I had gained enough knowledge and experience from internal medicine rotation, probably a crucial concern for a medical student who newly started the clinical rotations. Fortunately, internal medicine had a long history of using e-learning modalities, therefore my medical education did not face any unusual changes, at least in aspects of learning that have always been delivered to students virtually.

For using educational content, students should refer to the specially designed website (www.moodle.migel.ir), which contains educational materials for internal medicine courses, including cardiology, pulmonology, hematology, endocrinology, rheumatology, gastroenterology, and nephrology, in the form of both texts and movies for physical examination. Also, each course has assignments that update each week, mostly related to students' abilities towards searching and understanding scientific articles in the field. There was also a short exam with three questions for three courses every night, mostly Multiple-Choice Questions (MCQs); however, some questions occurred to be cases; for instance, once I was asked to type my interpretation of a chest X-ray.

The prominent feature of the website was scheduling, which allows the students to focus on a particular topic. Also, there is a feature that allows students to chat regarding a topic or question and even share related articles. From 2020/2/22 to 2020/6/10, I was at home; however, I continued my education through the website, and after that, I attended the educational program in the hospital, but still, the website was a great help since both mornings, and educational rounds were shortened. During two months of my internal medicine rotation, I was asked to complete my logbook on the website, and it was more efficient for me compared to previous paper-based logbooks. I could type a brief review of morning cases, my activities during the day, and, more importantly, new educational points of the day. Moreover, I could attach articles or pictures of tables of textbooks. Besides, before the final exam, reviewing my virtual logbook was a great help for me. Exams were online, a combination of MCQs and case-based questions with an emphasis on knowledge of history taking and physical examination. Certainly, I was not the only junior medical student who faced the COVID-19 on the first day of his/her clinical rotation, but I am not sure if all other students had the chance to have access to suitable resources for virtual medical education. Thanks to the internal medicine department of the hospital, medical students have access to a well-developed website, with a long history of function-

Copyright (c) 2020, Journal of Medical Education. This is an open-access article distributed under the terms of the Creative Commons Attribution-NonCommercial 4.0 International License (http://creativecommons.org/licenses/by-nc/4.0/) which permits copy and redistribute the material just in noncommercial usages, provided the original work is properly cited. 
ing, which shows the importance of utilizing new and efficient methods for education, including e-learning modalities, that is a great help during the pandemic.

Improving medical education should be a continuous process, which is not limited to the COVID-19 pandemic. As a medical student, I think my good experience with the aforementioned website is an example of successful virtual medical education $(2,3)$, which reveals several opportunities for Iranian universities to improve medical education with an emphasis on individualized, research-based, case solving education.

\section{Acknowledgments}

I would like to thank Dr. Pourfarzam, the chief of the internal medicine department of Mostafa Khomeini Hospital, that has made a great effort to establish this website, named Mostafa hospital Internal Group Electronic Learning (MIGEL), by collaboration with other professors of internal medicine department that I am grateful. Also, I would like to thank Dr. Jouhari, the Dean Deputy for Educational Affairs of the School of Medicine of Shahed Univer- sity that has facilitated virtual medical education during the COVID-19 pandemic.

\section{Footnotes}

Authors' Contribution: H.Y. was the only author and participated in all study concept and design and drafting of the manuscript.

Conflict of Interests: The author declares no conflict of interest.

Funding/Support: There was no funding.

\section{References}

1. Tabatabai S. COVID-19 impact and virtual medical education. J Adv Med Educ Prof. 2020;8(3):140-3. doi: 10.30476/jamp.2020.86070.1213. [PubMed: 32802908]. [PubMed Central: PMC7395196].

2. Saeed Khabiri S. Preparing practical in-person evidence-based journal club in COVID-19 crisis. J Adv Med Educ Prof. 2020;8(3):146-7. doi: 10.30476/jamp.2020.86217.1225. [PubMed: 32802910]. [PubMed Central: PMC7395202].

3. Hussein NR, M. Saleem ZS, Musa DH, Ibrahim N, Naqid IA. Impact of COVID-19 on the medical education: Experience from kurdistan region of iraq. J Med Edu. 2020;19(1). e106889. doi: 10.5812/jme.106889. 